\title{
Modelling and Forecasting of Residential Electricity Consumption in Nigeria Using Multiple and Quadratic Regression Models
}

\author{
Isaac Amazuilo Ezenugu ${ }^{1}$, Swinton Chisom Nwokonko ${ }^{1}$, Idorenyin Markson ${ }^{2}$ \\ ${ }^{1}$ Department of Electrical/Electronic Engineering, Imo State University, Owerri, Nigeria \\ ${ }^{2}$ Department of Mechanical Engineering, University of Uyo, Uyo, Nigeria
}

Email address:

isaac.ezenugu@yahoo.com (I. A. Ezenugu)

\section{To cite this article:}

Isaac Amazuilo Ezenugu, Swinton Chisom Nwokonko, Idorenyin Markson. Modelling and Forecasting of Residential Electricity Consumption in Nigeria Using Multiple and Quadratic Regression Models. American Journal of Software Engineering and Applications.

Vol. 6, No. 3, 2017, pp. 99-104. doi: 10.11648/j.ajsea.20170603.17

Received: January 30, 2017; Accepted: March 30, 2017; Published: June 23, 2017

\begin{abstract}
In this paper statistical analysis of the residential electricity demand in Nigeria is presented Particularly, multiple regression model with one period lagged and quadratic regression model without interactions were used to estimate residential electricity consumption and to forecast long- term residential demand for electricity based on annual data over the period 20062014. For the regression models' explanatory variable, population which is a socio economic variable is used along with temperature which is a climatic variable are used. The results showed that the quadratic regression model without interactions was more accurate due to the fact that it has the highest coefficient of determinant of 93.87 and the least value of Root Mean Square Error (RMSE) of 52.77as compared to the multiple regression model with one period lagged of the dependent variable with coefficient of determinant of 93.50 and RMSE of 53.16. The quadratic regression model was then selected and used to forecast the residential electricity demand in Nigeria for the years 2015 to 2029.
\end{abstract}

Keywords: Quadratic Regression Model, Regression Model Without Interactions, Multiple Linear Regression Model, Forecasting, Residential Electricity Demand

\section{Introduction}

Electricity is one of the most important commodities for the development of any nation [1-3]. Yet, electricity shortage still remains one of the main challenges facing the Nigeria nation [4-8]. This problem has been attributed to the inability of the electricity supply to meet the consumer demand [9-11]. The phenomenal increase in the population, economic activities as well as lack of maintenance of the existing power stations has also contributed to this problem [12-17]. More especially, with privatization at the power generation sector, more independent power generation stations are being installed. It is required that adequate plan for meeting the energy demand for different sectors and in this case, the residential sector should be considered. Available studies have focused on the integrated power demand for Nigeria. However, such model is not suitable for planning in many cases since there are different tariff for different power consumer sector.
Moreover, available studies have worked on power demand models data up to 2005. Models and analysis based on more recent data is essential, especially the one that identifies and focuses on the diverse consumer categories. In the research, the problem is on residential, electricity demand, modelling and forecasting for Nigeria.

\section{Methodology}

Residential electricity consumption in Nigeria is modelled using multiple regression model with one period lagged [18-27] and quadratic regression model [28-31]. Performance evaluation of the two models were also performed using Root Mean Square Error (RMSE), coefficient of determination $\left(\mathrm{R}^{2}\right)$ and $\mathrm{F}$ test. Data on residential electricity consumption (MW/h), between 2006-2014 were obtained from Central Bank of Nigeria Statistical Bulletin [32] while data on temperature $\left({ }^{\circ} \mathrm{C}\right)$ and population were obtained from the 
Bulletin of the National Bureau of Statistics [33]. The data span between 2006 and 2014.

\subsection{Model 1: Multiple Regression with One Period Lagged Dependent Variable}

The multiple regression model with one period lagged dependent variable expresses electricity consumption $\left(E_{t}\right)$ as a linear function of Population $(\mathrm{P})$ and Temperature $\left(\mathrm{T}_{t}\right)$ as follows:

$$
\begin{gathered}
E_{t}=f\left(P_{t}, T_{t}, E_{t-1}\right) \\
E_{t}=\alpha_{0}+\alpha_{1} P_{t}+\alpha_{2} T_{t}+\alpha_{3} E_{t-1}+\varepsilon_{t}
\end{gathered}
$$

Where $\alpha_{0}$ is the intercept, $\alpha_{1}, \alpha_{2}$ and $\alpha_{3}$ are the contributions of Population (P) and Temperature (T) respectively.

Econometric Views (EViews) statistical package is used to perform the regression from which the values of the intercept $\alpha_{0}$ and the regression coefficients $\alpha_{1}, \alpha_{2}$ and $\alpha_{3}$ are obtained for the multiple regression model.

\subsection{Model 2: Quadratic Regression Model Without Interaction}

$$
E_{t}=\alpha_{0}+\alpha_{1} P_{t}+\alpha_{2} T_{t}+\alpha_{3} P_{t}^{2}+\alpha_{4} T_{t}^{2}+\varepsilon_{t}
$$

Making $\varepsilon_{t}$ the subject gives;

$$
\varepsilon_{t}=E_{t}-\alpha_{0}-\alpha_{1} P_{t}-\alpha_{2} T_{t}+\alpha_{3} P_{t}^{2}+\alpha_{4} T_{t}^{2}
$$

Sum of the square of the error, $\mathrm{S}$ is given as;

$$
S=\sum_{t=1}^{n} \varepsilon_{t}^{2}
$$

Minimizing S gives;

$$
S=\sum_{t=1}^{n}\left(E_{t}-\alpha_{0}-\alpha_{1} P_{t}-\alpha_{2} T_{t}+\alpha_{3} P_{t}^{2}+\alpha_{4} T_{t}^{2}\right)^{2}
$$

Again, Econometric Views (EViews) statistical package is used to perform the regression from which the values of the intercept $\alpha_{0}$ and the regression coefficients $\alpha_{1}, \alpha_{2} \alpha_{3}$ and $\alpha_{4}$ are obtained for the quadratic regression model with interaction.

\subsection{Validation and Diagnostic Criteria}

\subsubsection{F-Test}

To check the goodness of fit of the models, $\mathrm{F}$ test is use and it is given as:

$$
F=\frac{M S R}{M S E}
$$

$$
M S R=\frac{S S R}{P-1}
$$

Where $P$ is the number of parameters

$$
M S E=\frac{S S E}{n-P}
$$

Where $n$ is the number of observation

The sum of square Total, SST is given as;

$$
\mathrm{SST}=E_{t}^{1} E_{t}-\left(\frac{1}{n}\right) E_{t}^{1} J E_{t}
$$

Sum of square regression, SSR, can be calculated for each model as follows:

$$
\begin{aligned}
& \operatorname{SSR}\left(\text { Model 1) }=\alpha_{d}^{1} U_{d}-\left(\frac{1}{n}\right) E_{t}^{1} J E_{t}\right. \\
& \operatorname{SSR}\left(\text { Model 2) }=\alpha_{e}^{1} U_{e}-\left(\frac{1}{n}\right) E_{t}^{1} J E_{t}\right.
\end{aligned}
$$

Where, $\mathrm{J}$ is the matrix,

$$
\text { Sum of square Error }(\mathrm{SSE})=\mathrm{SST}-\mathrm{SSR}
$$

\subsubsection{Coefficient of Determination}

The coefficient of determination shows the percentage of the variation in the dependent variable explained by the independent variables. It is given as

$$
r^{2}=\frac{S S R}{S S T}
$$

\subsubsection{Root Mean Square Error (RMSE)}

The square of the sum of square of differences between the predicted and observed value divided by the number of observation: It can be expressed mathematically as:

$$
R M S E=\sqrt{\frac{1}{n} \sum_{i=1}^{n}\left(E_{t}-\hat{E}_{t}\right)^{2}}
$$

\section{Result and Discussion}

Table 1 shows the model parameters and performance measures for multiple regression with one period lagged of the dependent variable. From the results in Table 1, the multiple regression with one period lagged of the dependent variable is given as;

$$
E_{t}=489.67+16.02 P_{t}-40.12 T_{t}+0.314 E_{t-1}
$$

The coefficient of determination $r^{2}$ of 0.935 shows that $93.5 \%$ of the variation in residential electricity consumption was accounted for by the multiple regression with one period lagged of the dependent variable. The contribution of 
population $\left(\alpha_{1}=16.02\right)$ is positive meaning that as population increases, residential electricity consumption also increases.

Table 2 and figure 1 show the actual and the predicted residential electricity consumption in Nigeria for the years 2007 to 2014.

Table 1. Estimates of the model parameters and performance measures for the multiple regression with one period lagged of the dependent variable.

\begin{tabular}{lllllll}
\hline Model parameters & Coefficients & SST & SSE & SSR & $\mathbf{r}^{2}(\%)$ & RMSE \\
\hline Constant $\left(\alpha_{0}\right)$ & 489.67 & 348190.99 & 22608.72 & 325582.27 & 93.5 & 53.16 \\
$\mathrm{P}_{\mathrm{t}(\alpha 1)}$ & 16.02 & & & & \\
$\mathrm{~T}_{\mathrm{t}(\alpha 2)}$ & 40.12 & & & & \\
$\mathrm{E}_{\mathrm{t}-1(\mathrm{a}) \mathrm{l}}$ & 0.314 & & & & \\
\hline
\end{tabular}

SSR $=$ Sum of Square Regression, SST $=$ Sum of Square Total, SSE $=$ Sum of Square Error, RMSE $=$ Root Mean Square Error.

Table 2. Values of actual and predicted electricity consumption using the multiple regression with one period lagged of the dependent variable.

\begin{tabular}{lll}
\hline Year & Actual(MW/h) & Predicted(MW/h) \\
\hline 2007 & 1151.94 & 1146.09 \\
2008 & 1165.72 & 1132.86 \\
2009 & 1104.54 & 1226.58 \\
2010 & 1365.50 & 1319.85 \\
2011 & 1401.01 & 1361.86 \\
2012 & 1437.43 & 1393.54 \\
2013 & 1474.81 & 1493.77 \\
2014 & 1513.15 & 1539.56 \\
\hline
\end{tabular}

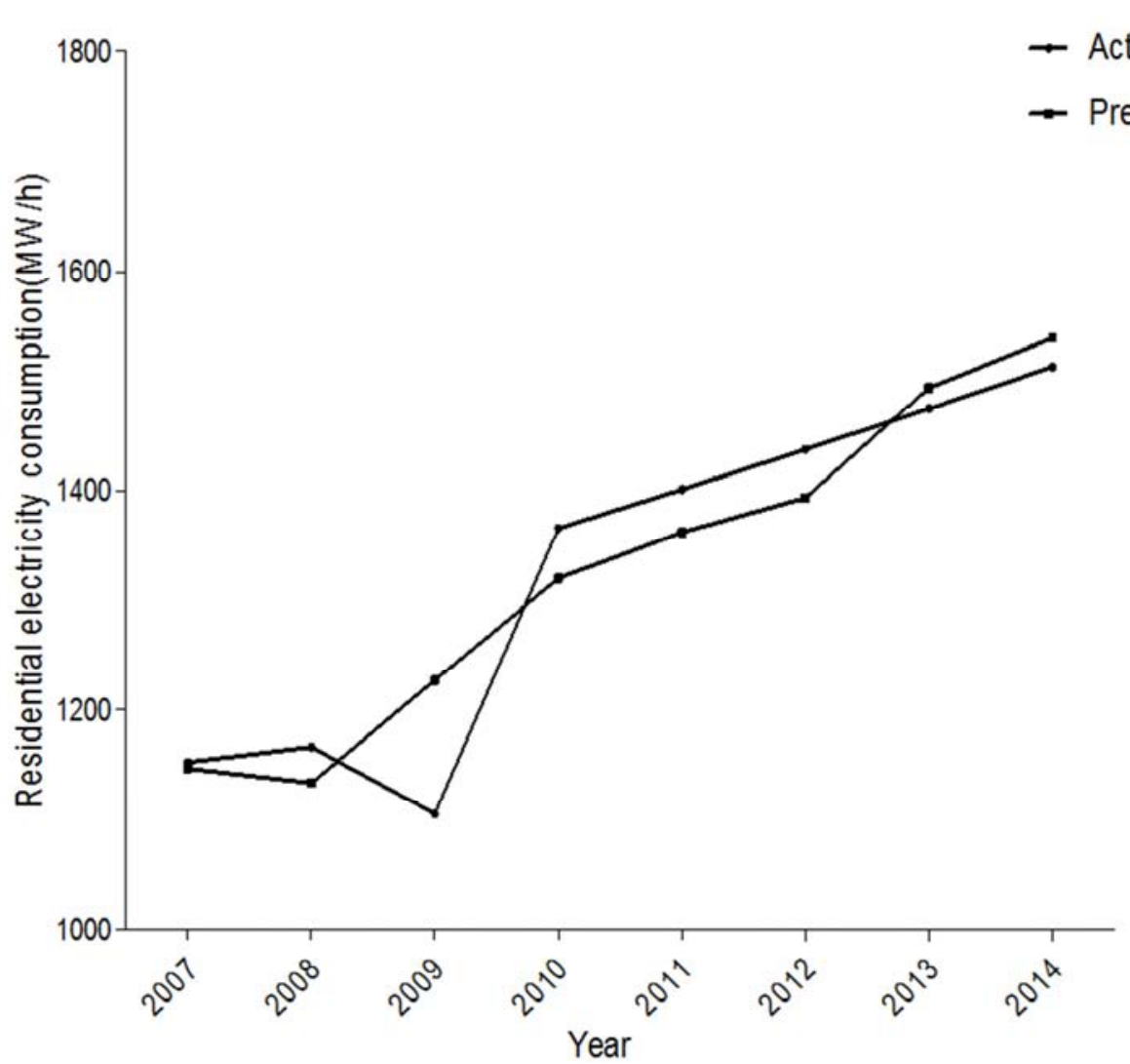

Figure 1. Graph of the Actual and Predicted Residential Electricity Consumption for the multiple regression with one period lagged of the dependent variable.

Table 3 shows the model parameters and performance measures for the quadratic regression with interaction. From the results in Table 3, the quadratic regression with interaction is given as;

$$
E_{t}=152014.90+386.57 P_{t}-10855.92 T_{t}+0.40 P_{t}^{2}+177.38 T_{t}^{2}-7.05 P_{t} T_{t}
$$

The r-square value of 0.9389 indicates that $93.89 \%$ of the variation in residential electricity consumption was explained by the quadratic regression with interaction. The model also reveals that the linear term of population $\left(\alpha_{1}=386.57\right)$ and the quadratic term for temperature $\left(\alpha_{2}=177.38\right)$ have positive contribution to residential electricity consumption. This result indicates that as 
these variables increases in value, residential electricity consumption also increases. Summary results of the actual and predicted residential electricity consumption in Nigeria for the years 2007 to 2014 are as shown in Table 4 and figure 2.

Table 3. Estimates of the model parameters and performance measures for the quadratic regression with interaction.

\begin{tabular}{|c|c|c|c|c|c|c|}
\hline Model parameters & Coefficients & SST & SSE & SSR & $\mathbf{r}^{2}(\%)$ & RMSE \\
\hline Constant $(\alpha 0)$ & 152014.90 & 348190.99 & 27444.52 & 320746.47 & 0.9389 & 52.77 \\
\hline $\mathrm{P}_{\mathrm{t}(\alpha 1)}$ & 386.57 & & & & & \\
\hline $\mathrm{T}_{\mathrm{t}(\alpha 2)}$ & -10855.92 & & & & & \\
\hline $\mathrm{T}^{2(\alpha 4)}$ & 177.38 & & & & & \\
\hline $\mathrm{P}_{\mathrm{t}} \mathrm{T}_{\mathrm{t}(\alpha .5)}$ & -7.05 & & & & & \\
\hline
\end{tabular}

$\mathrm{SSR}=$ Sum of Square Regression, SST $=$ Sum of Square Total, SSE $=$ Sum of Square Error, RMSE $=$ Root Mean Square Error.

Table 4. Values of actual and predicted electricity consumption using the quadratic regression with interaction ( $Q R I)$.

\begin{tabular}{lll}
\hline Year & Actual(MW/h) & Predicted(MW/h) \\
\hline 2006 & 894.11 & 948.39 \\
2007 & 1151.94 & 1045.49 \\
2008 & 1165.72 & 1214.45 \\
2009 & 1104.54 & 1179.20 \\
2010 & 1365.50 & 1317.55 \\
2011 & 1401.01 & 1400.75 \\
2012 & 1437.43 & 1459.71 \\
2013 & 1474.81 & 1480.52 \\
2014 & 1513.15 & 1515.73 \\
\hline
\end{tabular}

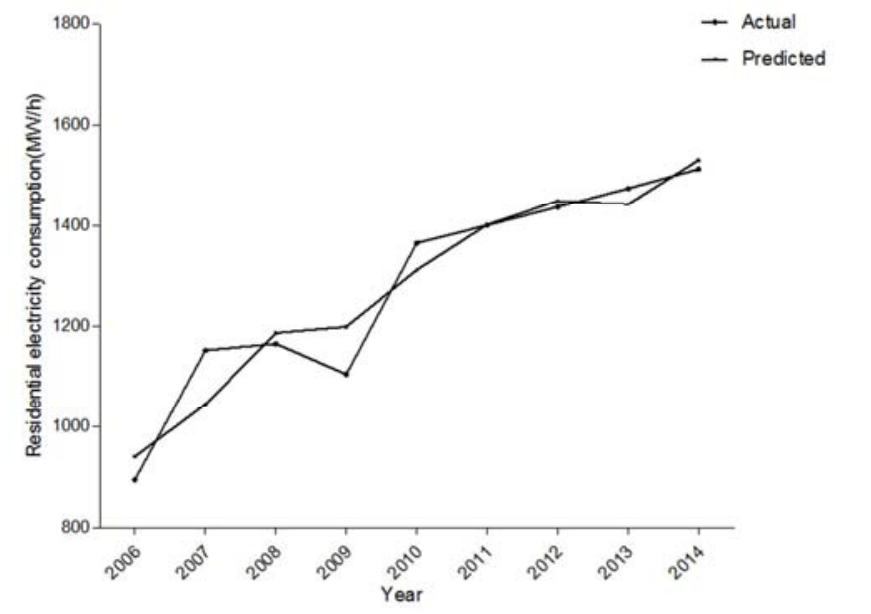

Figure 2. Graph of the actual and predicted residential electricity consumption for the quadratic regression with interaction (QRI).

Table 5. Comparison of the Performance of the two Models.

\begin{tabular}{lll}
\hline Models & $\mathbf{r}^{\mathbf{2}} \mathbf{( \% )}$ & $\mathbf{R M S E}$ \\
\hline $\begin{array}{l}\text { The multiple regression with one period lagged of the } \\
\text { dependent variable. }\end{array}$ & 93.50 & 53.16 \\
\begin{tabular}{l} 
The quadratic regression with interaction (QRI) \\
\hline
\end{tabular} & 93.87 & 52.77 \\
\hline
\end{tabular}

Table 5 shows performance evaluation of the two competing models. The result shows that the two models were highly competitive as the $\mathrm{r}$ - square obtained for each model were very high. The quadratic regression with interaction gave the highest value of coefficient of determination $\left(\mathrm{r}^{2}\right)$ and the least Root Mean Square Error (RMSE) compared with multiple regression with one period lagged of the dependent variable. Hence, quadratic regression with interaction is recommended for forecasting residential electricity consumption in Nigeria.
The population for 2015 and 2019 were projected using the formula;

$$
P_{t}=P_{t-1}(1+r)^{n}
$$

Where $\mathrm{n}=$ number of years, $P_{t-1}=$ previous year population, $P_{t}=$ the population of the year to be estimated and $\mathrm{r}$ is the population growth rate of Nigeria which is given to $3.2 \%$ according to 2006 population census. Also, the temperature was predicted using simple linear regression where a simple regression model of temperature versus time was fitted as follows;

$$
T=a_{0}+a_{1} t
$$

The model parameters $a_{0}$ and $a_{1}$ were estimated using Microsoft excel programme. $a_{0}=34.602, a_{1}=0.0613$

$$
T=34.602+0.0613 t+\varepsilon_{t}
$$

$\mathrm{t}=$ time, $t=10, \cdots, 24$

Table 6 and figure 3 show the forecasted residential electricity consumption in Nigeria from 2015-2029 using the quadratic regression with interaction. From the results in Table 5, the Residential Electricity Consumption in Nigeria will reach $6521.09 \mathrm{MW} / \mathrm{h}$ in the year 2029 .

Table 6. The Forecast values for Residential Electricity Consumption (2015-2029).

\begin{tabular}{lllll}
\hline S/N & Year & Population (Million) & Temp. $\left({ }^{\circ} \mathbf{C}\right)$ & Predicted $(\mathbf{M W} / \mathbf{h})$ \\
\hline 1 & 2015 & 186.84 & 33.99 & 2937.90 \\
2 & 2016 & 192.82 & 33.93 & 3116.81 \\
3 & 2017 & 198.99 & 33.87 & 3305.97 \\
4 & 2018 & 205.36 & 33.81 & 3504.57 \\
5 & 2019 & 211.93 & 33.74 & 3714.71 \\
6 & 2020 & 218.71 & 33.68 & 3934.14 \\
7 & 2021 & 225.71 & 33.62 & 4166.97 \\
8 & 2022 & 232.94 & 33.56 & 4410.53 \\
9 & 2023 & 240.39 & 33.5 & 4667.68 \\
10 & 2024 & 248.08 & 33.44 & 4937.62 \\
11 & 2025 & 256.02 & 33.38 & 5222.63 \\
12 & 2026 & 264.21 & 33.31 & 5522.81 \\
13 & 2027 & 272.67 & 33.25 & 5838.59 \\
14 & 2028 & 281.39 & 33.19 & 6171.24 \\
15 & 2029 & 290.4 & 33.13 & 6521.09 \\
\hline
\end{tabular}




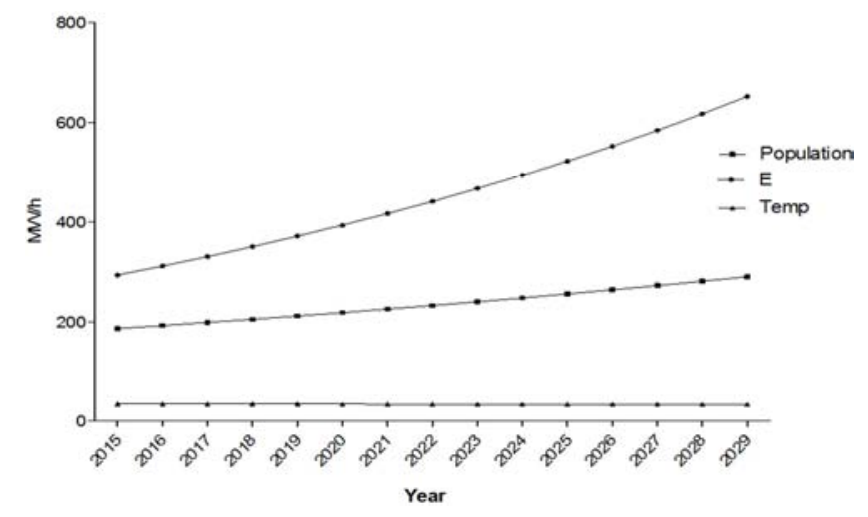

Figure 3. Graph of Forecasted Residential Electricity Consumption (2015-2029).

\section{Conclusion}

The paper statistical analysis of the residential electricity demand in Nigeria is presented, employing annual data over the period 2006-2014. Particularly, multiple regression model with one period lagged and quadratic regression model without interactions were used to estimate residential electricity consumption and to forecast long- term residential demand for electricity. The results showed that the quadratic regression model without interactions was more accurate due to the fact that it has the highest coefficient of determinant and the least value of Root Mean Square Error as compared to the multiple regression model with one period lagged of the dependent variable. The quadratic regression model was then selected and used to forecast the residential electricity demand in Nigeria for the years 2015 to 2029 .

\section{References}

[1] Othieno, H., \& Awange, J. (2015). Energy Resources in Africa: distribution, opportunities and challenges. Springer.

[2] Otieno, H. O., \& Awange, J. L. (2006). Energy resources in East Africa: Opportunities and challenges. Springer Science \& Business Media.

[3] Ahuja, D., \& Tatsutani, M. (2009). Sustainable energy for developing countries. SAPI EN. S. Surveys and Perspectives Integrating Environment and Society, (2.1).

[4] Onuoha, F. C., Ichite, C. M., \& George, T. A. Political, Economic and Security Challenges Facing President Buhari. Technical Report Of Al Jazeera Center for Studies

[5] Mohammed M. A., Babagana G., Bitrus K. H. and Mustapha A. H. (2015) CHALLENGES TO ENERGY SUSTAINABILITY IN NIGERIA AS A DEVELOPING NATION AND THE WAY FORWARD. APPLIED RESEARCH JOURNAL. Vol.1, Issue, 2, pp.46-50, April, 2015

[6] Ogbeidi, M. M. (2012). Political leadership and corruption in Nigeria since 1960: A socio-economic analysis. Journal of Nigeria Studies, 1(2).

[7] Dike, V. E. (2010). Review of the challenges facing the Nigerian economy: Is national development possible without technological capability. Journal of Sustainable Development in Africa, 12(5), 95-112.

[8] Kennedy-Darling, J., Hoyt, N., Murao, K., \& Ross, A. (2008). The energy crisis of Nigeria: an overview and implications for the future. The University of Chicago, Chicago.

[9] Ofoegbu, G. N., \& Emengini, S. E. (2013). Recovery of Cost of Electricity Supply in the Nigerian Power Sector. University of Nigeria, Enugu Campus, Enugu State, Nigeria.

[10] Adoghe, A. U., Odigwe, I. A., \& Igbinovia, S. O. (2009). Power Sector Reforms-Effects on Electric Power Supply Reliability and Stability in Nigeria. International Journal of Electrical and Power Engineering, 3(1), 36-42.

[11] Oyedepo, S. O. (2013). Energy in perspective of sustainable development in Nigeria. Sustainable Energy, 1(2), 14-25.

[12] Hove, M., Ngwerume, E., \& Muchemwa, C. (2013). The urban crisis in Sub-Saharan Africa: A threat to human security and sustainable development. Stability: International Journal of Security and Development, 2(1).

[13] Oyedepo, S. O. (2012). Energy and sustainable development in Nigeria: the way forward. Energy, Sustainability and Society, 2(1), 1 .

[14] Maxwell U. N., Nnena F. E., Uloma J. [2014] Comparative Analysis of Electricity Consumption among Residential, Commercial and Industrial Sectors of the Nigeria's Economy. Journal of Energy Technologies and Policy, Vol.4, No.3, 2014

[15] Sambo, A. S., Garba, B., Zarma, I. H., \& Gaji, M. M. (2012). Electricity generation and the present challenges in the Nigerian power sector. Journal of Energy and Power Engineering, 6(7), 1050.

[16] Ondiege, P. E. T. E. R., Moyo, J. M., \& Verdier-Chouchane, A. U. D. R. E. Y. (2013). Developing Africa's infrastructure for enhanced competitiveness. In World Economic Forum, the African Competitiveness Report (Vol. 2013, pp. 69-92).

[17] Scott-Emuakpor, A. (2010). The evolution of health care systems in Nigeria: Which way forward in the twenty-first century. Nigerian Medical Journal, 51(2), 53.

[18] Onochie, U. P., Egware, H. O., \& Eyakwanor, T. O. (2015). The Nigeria Electric Power Sector (Opportunities and Challenges). Journal of Multidisciplinary Engineering Science and Technology (JMEST), 2(4).

[19] OLUSEGUN, A. O. (2016). PUBLIC-PRIVATE PARTNERSHIP AS A TOOL FOR INFRASTRUCTURAL GROWTH IN NIGERIA: A FOCUS ON NIGERIA'S ELECTRCITY SECTOR.

[20] Ogunleye, E. K. (2016). Political economy of Nigerian power sector reform (No. UNU-WIDER Research Paper wp2016-009). World Institute for Development Economic Research (UNU-WIDER).

[21] Joseph, I. O. (2014). Issues and challenges in the Privatized Power Sector in Nigeria. Journal of Sustainable Development Studies, 6(1), 161.

[22] Folorunso, O., \& Olowu, T. The Nigerian Power System Till Date: A Review. International Journal of Advance Foundation and Research in Science \& Engineering (IJAFRSE), 1(5).

[23] Forst, F. G. (1992). Forecasting restaurant sales using multiple regression and Box-Jenkins analysis. Journal of Applied Business Research, 8(2), 15. 
[24] Goel, A., \& Goel, A. (2014). Regression Based Forecast of Electricity Demand of New Delhi. International Journal of Scientific and Research Publications, 437.

[25] Benli, T. O. (2016). A Comparison of Nineteen Various Electricity Consumption Forecasting Approaches and Practicing to Five Different Households in Turkey. arXiv preprint arXiv:1607.05660.

[26] Owda, H. M., Omoniwa, B., Shahid, A. R., \& Ziauddin, S. (2014). Using Artificial Neural Network Techniques for Prediction of Electric Energy Consumption. arXiv preprint arXiv: 1412.2186

[27] Mati, A. A., Gajoga, B. G., Jimoh, B., Adegobye, A., \& Dajab, D. D. (2009). Electricity demand forecasting in Nigeria using time series model. The Pacific Journal of Science and Technology, 10(2), 479-485.

[28] Wang, Y., Zhang, Y., Zhang, F., \& Yi, J. (2013). Robust quadratic regression and its application to energy-growth consumption problem. Mathematical Problems in Engineering, 2013.

[29] Alkan, Ö., Genç, A., Oktay, E., \& Çelik, A. K. (2013). Electricity Consumption Analysis Using Spline Regression Models: The Case of a Turkish Province. Asian Social Science, 9(7), 231-240.

[30] Krese, G., Prek, M., \& Butala, V. (2012). Analysis of building electric energy consumption data using an improved cooling degree day method. Strojniški vestnik-Journal of Mechanical Engineering, 58(2), 107-114.

[31] Kumru, M., \& Kumru, P. Y. (2015, March). Calendar-based short-term forecasting of daily average electricity demand. In Industrial Engineering and Operations Management (IEOM), 2015 International Conference on (pp. 1-5). IEEE.

[32] National Bureau of Statistics, 2015.

[33] Agboola, B. M., \& Adeyemi, J. (2013). Projecting Enrollment for Effective Academic Staff Planning in Nigerian Universities. Educational Planning, 21(1). 